\title{
Erratum to: Robot-assisted modifications of gait in healthy individuals
}

\author{
Seok Hun Kim • Sai K. Banala • \\ Elizabeth A. Brackbill • Sunil K. Agrawal • \\ Vijaya Krishnamoorthy $\cdot$ John P. Scholz
}

Published online: 10 April 2010

(C) Springer-Verlag 2010

\section{Erratum to: Exp Brain Res \\ DOI 10.1007/s00221-010-2187-5}

The authors apologize for the errors in the legend of Fig. 6 . The corrected legend is as follows:

Average ratio in integrated hip extensor and knee flexor moments between each of the post-training tests and the baseline test. Values greater or less than 1.0 indicate an increase or decrease, respectively, of the joint moment relative to the baseline test. $F F C+V G$ force-field constraint plus visual guidance, $F F C$ force-field constraint, $V G$ visual guidance, IPT immediate post-training, $R 1$ retention 1 , $R 2$ retention 2. Error bars represent SEM

The online version of the original article can be found under doi:10.1007/s00221-010-2187-5.

\section{S. H. Kim}

School of Physical Therapy and Rehabilitation Sciences,

University of South Florida, Tampa, FL 33612, USA

e-mail: skim@health.usf.edu

S. K. Banala - E. A. Brackbill · S. K. Agrawal

Department of Mechanical Engineering, University of Delaware,

Newark, DE 19716, USA

V. Krishnamoorthy

Division of Physical Therapy, Department of Rehabilitation

Medicine, Emory University, Atlanta, GA 30322, USA

J. P. Scholz ( $\square)$

Department of Physical Therapy, University of Delaware,

307 McKinly Laboratory, Newark, DE 19716, USA

e-mail: jpscholz@udel.edu

J. P. Scholz

Biomechanics and Movement Science Program, University of

Delaware, Newark, DE 19716, USA 